\title{
Manejo Rápido para el Diagnóstico de la Pareja en la Consulta de Esterilidad
}

\author{
Fernando Cardona A. \\ M. D. Byron Ríos C. \\ M. D. \\ Aníbal Castañeda L. \\ M. D. \\ Jesús De Los Ríos O. \\ M. D. \\ María Cristina Posada de De Los Ríos Enfermera
}

\section{INTRODUCCION}

Si bien es cierto que la pareja que acude a un centro para el estudio de la esterilidad, lleva meses o años con su problema, también es verdadero que cuando se deciden a frontar el estudio pertinente presentan ellos una serie de inquietudes $y$ de interrogantes que les producen angustia más o menos manifiesta, y desean conocer lo más rápidamente posible la causa, o causas de sus trastornos en la fisiología de la reproducción para así tener al menos una visión panorámica del tiempo y de los tratamientos requeridos y una evaluación de la posibilidad de tener un hijo.

\section{METODOLOGIA}

\section{A. Inscripción}

En una oficina adecuada, en donde se lleva el registro de las parejas estudiadas se hace la inscripción respectiva, se anotan sus nombres $y$ direcciones del trabajo y del hogar, $y$, si es posible, el número telefónico para recordarles, la víspera, la cita y la hora de la consulta del día siguiente.

La primera vez se insiste en que es parte esencial de la metodología la entre- vista inicial de "la pareja" con el médico; en caso de contestar que por causas externas ello no es posible, se postergará para otra oportunidad ésta primera consulta. Con ello se logra uno de los objetivos básicos en este tipo de estudio: la eliminación de casos en los cuales uno de los cónyuges no está interesado en asistir y cooperar.

\section{B. Entrevista con la pareja}

Después de una breve introducción, que el médico aprovecha para constatar que se trata de una unión estable en donde esté justificada esta consulta, se les explica como, hasta ese momento, "Su Problema" deja de serlo para ellos y pasa a manos del equipo que se encargará del estudio. Se enseña, citando a Speroff $\left({ }^{*}\right)$ que estadísticamente, en grandes centros mundiales dedicados a estos problemas el factor masculino ocupa el $40 \%$, el factor femenino el $45 \%$ y en el $15 \%$ restante que no se llega aún, con los adelantos científicos que se poseen, a conocer la etiología. Se explica el esquema de trabajo para lograr en forma rápida un diagnóstico y luego cómo se procederá a una terapia racional tratando de corregir el factor o los factores que se apartan de los patrones normales. Para todo ello es ne- 
cesario que la próxima consulta, que efectuará la pareja donde el andrólogo, esté precedida de un óptimo espermograma completo con abstinencia de cinco días $y$ efectuando en él la dosificación de fructuosa inicial y a las cinco horas, y estudio morfológico, de motilidad y de progresión lineal espermática. Se recomienda que cuando la pareja acuda, en posterior consulta de nuevo al ginecólogo, la señora vaya sin efectuarse ningún lavado interno vaginal, ni haber tenido relaciones sexuales la víspera, para poder así valorar correctamente la citología hormonal tomada de la pared lateral dei tercio posterior de vagina en ese día y su correlación con el estudio de la secrección de endocerviz tomada en ésta misma consulta.

\section{Consulta Andrológica}

Se procede a una anamnesis con los antecedentes relacionados con la reproducción como orquitis, epidimitis, prostatitis, uretritis, varicocele, hidrocele, criptorquidia, parotiditis con lesión testicular, T. B. C. urogenital, trauma testicular y hernias inguinales. Se interroga sobre la conducta sexual desde la pubertad hasta el momento actual. Se hace un examen físico general y luego uno andrológico completo, siguiendo el modelo de historia diseñado para tal fin, en donde ya estarán los datos del espermograma efectuado previamente.

\section{Consulta Ginecológica}

Se hace una anamnesis general y se hace énfasis en los antecedentes relacionados a la telarquia, pubarquia y menarca, en los ciclos menstruales y en la fecina de la última menstruación. Se completa el interrogatorio general y se anota con detalle todo lo relacionado sobre la conducta sexual desde la pubertad hasta el momento actual. Se hace un exámen físico general y luego ginecológico, ciudándose de aplicar el espéculo vaginal sin lubricar o humedecerlo en suero fisiológico; se hace un examen en fresco de las células exfoliadas de la pared vaginal lateral del tercio posterior para ver si existe o no concordancia con el día del ciclo; allí mismo se práctica una toma de contenido endocervical y se estudia la filancia, la cristalización, el pH, los diferentes tipos de células que contiene para valorar igualmente la concordancia con el día del ciclo y la citología funcional y $\mathrm{s}$ ! existen signos de infección en esta secreción.

Posteriormente se hace histerometría y relación cuello-cuerpo, y finalmente una palpación bimanual abdomino-vaginal $y$ abdomino-rectal.

Se piden los exámenes pertinentes para efectuar una laparoscopia diagnóstica con anestesia general que se programa entre el 23 y 26 día del ciclo.

\section{E. Laparoscopia diagnóstica con Cromatoscopia}

Es éste uno de los pilares fundamentales del estudio rápido ginecológico en esterilidad, pues con la ayuda del laparoscopio se ve: a) la actividad de uno y otro ovario y si hay cuerpo amarillo reciente, b) si existe albugínea engrosada, c), si existe una de las variedades de poliquistosis ovárica, d) si hay agenesia ovárica uni o bilateral, e) si hay ovarios atróficos, f) si hay signos de endometriosis ovárica, g) si hay reacción peritoneal periovárica, h) si 
la pelvis menor está libre o existen adherencias que revelan la existencia de una inflamación anterior, i) si hay granulaciones tipo T. B. C., j) si hay focos de endometriosis, k) si el útero es de forma $y$ tamaño normal, I) si existen miomas, II) si las trompas tienen tamaño y formas normales, m) si están las trompas libres o con adherencias proximales o distales, n) si hay buena elasticidad tubárica, ol si las fimbrias tienen morfología normal, p) por medio de la cromatoscopia, si el paso del colorante es normal, o solo por una trompa y con dificultad, o si no pasa a la cavidad abdominal, q) cuando es requerido se hace biopsia de la gonada, con una pinza para tal fin, guiándose con el laparoscopio, y finalmente, se hace biopsia de endometrio en donde se pide su concordancia o no con el día real del ciclo y si existen cambios tipo inflamatorio que hagan sospechar por ejemplo en una endometriosis tipo T. B. C.

\section{F. Prueba de Huhner y diagnósti- cos logrados}

Para la quinta consulta ya se tiene el resultado de la biopsia de endometrio, pues la pareja es citada para el día 12 del ciclo siguiente y se les instruye para que tengan relaciones sexuales de acuerdo con las normas conocidas para una prueba de Huhner, se procede a ella y luego se les informa sobre el diagnóstico obtenido en cuanto al factor o los factores etiológicos de su esterilidad, ya sea andrológico, testicular o de las vías eferentes y anexos, ya sea ginecológico, ovárico, o tuboperitoneal, o uterino, ya sea mixto cervical, inmunológico, vaginal, (o coital) psicológico, o médico general.
Cuando es necesario se explican los exámenes adicionales requeridos y siempre se dialoga sobre el tratamiento que se elegirá, el tiempo aproximado que se empleará y las posibilidades de éxito en cuanto a obtener el hijo deseado.

\section{Resultados}

Con esta nueva metodología iniciada en Profamilia de Medellín, se han estudiado 155 parejas. Se ha logrado en estas cinco consultas clasificar los factores etioló gicos en los grupos ya descritos en $56.8 \%$. $\mathrm{Ha}$ sido necesario ordenar exámenes complementarios para obtener un diagnóstico o precisar el sitio de la lesión, como por ejemplo histerosalpingografías, pseudoembarazo con progestágenos por dos meses $y$ antes de sangría curetaje para buscar T. B. C., biopsias de la gonada, pruebas inmunológicas o dosificaciones hormonales por radioinmunoanálisis en un $14.8 \%$. Con este estudio rápido para el diagnóstico se ha presentado abandono antes de las cinco entrevistas en un $43.2 \%$.

\section{Comentario}

El manejo rápido para el diagnóstico de la pareja estéril tiene como pilares fundamentales, el sistemático estudio andrológico con examen físico completo y con espermograma morfológico y dinámico con dosificaciones de fructuosa; el completo examen ginecológico, valorando con la ayuda de la citología hormonal y de la secreción cervical y la biopsia endometrial, el funcionamiento ovárico que es confirmado con la visión qựe de ellos tiene por medio de la laparoscopia diagnóstica con cromatografía, que agrega al estudio anterior el conocimiento del fac- 
tor tubo-peritoneal y el uterino. Además la prueba de Huhner que orienta los factores cervicales puros o mixtos y el efectuar siempre las consultas con la pareja, permiten tomar conciencia de si existen problemas psicológicos que estén influyendo como factores etiológicos de disendocrinias.

Todo ello hace más ágil y funcional esta consulta que permitirá que ella no se quede sin terminar, y en un razonable número de casos, la meta buscada sin alcanzar.

Se presentó un $43.2 \%$ de abandono -cifra que se considera muy alta- antes de las cinco entrevistas por las siguientes causas:

a) El varón no se hizo el espermograma. b) El varón se enteró de su problema e inició o no el tratamiento, pero no volvió a la consulta como "pareja".

c) Ella no vino a la laparoscopia por problemas económicos o por temor a la anestesia o al examen.

d) Ella conoció los resultados de la laparoscopia que indicaban una microcirugía u otro tratamiento y no volvió como pareja.

\section{Resumen}

Se presenta un modelo de manejo rápido para el diagnóstico de la pareja estéril a base de estudio andrológico, ginecológico, laparoscopia y prueba de Hühner que permite en cinco consultas llegar a un diagnóstico etiológico en un alto porcentaje.

(*) Speroff L., Glass R. H., Kase N. Endocrinología Ginecológica e Infertilidad, Ed. Torey, Barcelona 1975. 